\title{
LA IMPORTANCIA DE IMPLEMENTAR UN PROGRAMA DE COMPLIANCE AMBIENTAL EN LAS EMPRESAS
}

\section{THE IMPORTANCE OF IMPLEMENT AN ENVIRONMENT COMPLIANCE PROGRAM IN BUSINESS COMPANIES}

Mtro. Leonel Lara Serna ${ }^{a}$

Dr. Octavio Ruíz Méndez ${ }^{b}$

${ }^{a}$ Universidad Veracruzana

Instituto de Investigaciones en Contaduría, leolara@uv.mx

${ }^{\mathrm{b}}$ Universidad Veracruzana

Facultad de Contaduría y Administración, Sistema de Enseñanza abierta

ocruiz@uv.mx

Fecha de recepción: 30 de octubre de 2020

Fecha de aceptación: 15 de diciembre de 2020

\section{RESUMEN}

La implementación de un modelo de compliance posiciona a las empresas entre sus competidores y le brinda la posibilidad de adecuarse fácilmente a otros mercados, pues significa que es versátil y posee la capacidad de adaptarse a las necesidades actuales del cliente, las cuales, precisamente, son determinantes para su permanencia y aceptación dentro de la sociedad. Es claro que, durante los últimos 30 años, el sector empresarial se ha enfocado en las necesidades y preocupaciones de la sociedad (que se conectan directamente con la globalización y estilo de vida) más que en la creación e imposición de productos, debido a que buscan brindar soluciones y atender conflictos propios de cada época.

A la vez, la inclusión de compliance permite que sea más fácil la gestión de operaciones, la previsión de riesgos, así como la consolidación de una imagen, ya que esta herramienta le agrega valor económico a la empresa, considerándose una inversión obligada.

Son muchos los parámetros que un buen programa de compliance debe cubrir, sin embargo, en este trabajo, se abordarán tres temas que son de suma importancia hoy en día: el compliance, el medio ambiente, -que se ha convertido en uno de los principales aspectos de 
regulación paras las empresas- y la fusión entre ellos, para mejorar la operatividad al margen del respeto de lo derechos humanos y el desarrollo sustentable.

PALABRAS CLAVE: Innovación, compliance, medio ambiente, derechos humanos, gestión.

\section{ABSTRACT}

The application of a compliance model allows companies to position themselves among their contenders and gives them the possibilities to easily adapt to their other markets, which means that it's flexible because it has the ability to touch current needs of the costumers; something that are decisive for their permanence and acceptance within society. It's clear that for the past 30 years, the business sector has focused on the needs and concerns of society (which are directly connected to globalization and lifestyle) rather than the creation and imposition of products, because they seek provide solutions and address conflicts specific to each era.

At the same time, the inclusion of a compliance model helps the operation and risk managements and image consolidation easier, since this tool adds economic value to the company, which is why they are in front of a required investment.

There are exclusive parameters that a good compliance program must cover, however, in this work, we'll talk about three issues that are of the most importance today: compliance, the environment, which has become one of the main regulatory mechanism for business companies and the merger between them, to improve operations regardless of respect human rights.

KEYWORDS: Innovation, compliance, environment, human rights, management.

\section{INTRODUCCIÓN}

Actualmente, el éxito de una empresa dependerá del nivel de innovación que posean los productos o servicios que ofrezca, pero sobre todo, del nivel de adaptación que posean en la vida del usuario que los ha elegido, por lo que es importante conocer el público y el medio 
al que se dirigen para saber cómo se dará a conocer, de qué forma, a través de qué medios, bajo qué circunstancias o contra quién, sin olvidar otros factores imprescindibles como el cumplimiento de obligaciones jurídicas y sociales, que se han vuelto vitales en esta era de globalización por la que se transita y cuyas condiciones, obedecen modelos internacionales, que si bien conforman sistemas altamente rigurosos de evaluación, otorgan la posibilidad de incrementar el alcance que todo empresario desea.

Es bien sabido que para lograr estos objetivos se deben estructurar bases sólidas de organización y logística, que a la vez conformen áreas que trabajarán tareas específicas y ayudarán a lograr los propósitos planteados para desarrollar todas las funciones; sin embargo, esto no es suficiente si se toma en consideración los peligros a los que una empresa podría enfrentarse por errores que puedan cometer los colaboradores dentro y fuera de esta, mismos que no están exentos de sanciones legales y que podrían incluso, causar daños irreparables tanto a la imagen como a la existencia de la misma.

Implementar un sistema de compliance como parte de la estructura de la persona jurídica, hoy en día es una decisión inteligente, pues este modelo no solo está enfocado para el cumplimiento normativo derivado de los preceptos legales a los que la empresa se debe adherir, sino que va más allá; este modelo es novedoso porque se centra en la prevención, detección y la gestión de los riesgos que como se mencionó, pueden dañar la empresa de diversas formas y cuyo origen podría no encontrarse en la persona que cometió el error, sino en la falta de prevención.

El modelo de compliance debe ser versátil para adaptarlo en todas las actuaciones que se realicen, por lo que además de incluir preceptos legales, deben atenderse criterios éticos que puedan ser aplicados al interior de la empresa, con el fin de evitar sanciones pero también de contribuir a la colectividad.

Sin duda, son muchos los rubros que pueden y deben cubrirse en un modelo de compliance, pero en esta ocasión, el trabajo se enfocará en el medio ambiente debido a la preocupación e importancia que posee como ciudadanos y para las naciones, principalmente por la situación que se enfrenta y porque lamentablemente se es consciente de que las malas 
actuaciones por parte del sector industrial y empresarial en décadas pasadas provocaron en gran porcentaje esta problemática.

Si una empresa toma en cuenta el aspecto ambiental dentro de su modelo de compliance, estará cumpliendo íntegramente con el objeto de bienestar social y perdurabilidad, además, estará atendiendo riesgos y previniendo procedimientos que actualmente están descritos y regulados en nuestro país y por si fuera poco, atendería a la vez, principios fundamentales relacionados con los derechos humanos y con el valor que el medio ambiente posee.

El auge del compliance en países anglosajones ha permitido que las empresas incrementen su valor económico y social al atender mediante esta herramienta, aspectos más relacionados con ética, empatía, respeto y labor social de manera interna entre los colaboradores, cuyas actuaciones debían atender en todo momento, lo estipulado en el compliance y que a la par, se diera la oportunidad de mejorar sus relaciones de trabajo, así como el cumplimiento de las normas nacionales e internacionales.

Se desarrolló incluso, la figura del compliance officer para verificar que se le diera un cumplimiento adecuado y que pudiera exteriorizarse fácilmente la presencia de los preceptos en cada acción que la empresa realice. Además, la creación de esta figura, logró el incremento de oportunidades laborales al ser un área especializada e integrada de manera permanente dentro de la estructura de trabajo.

Sin embargo, en México, la figura del compliance es relativamente nueva, por lo tanto, existe un cierto desconocimiento y confusión acerca de su conceptualización, aplicación, alcances, áreas de oportunidad, etc., pues no al no ser muy clara o incluso nula su existencia en la mayoría de las empresas, son muy altas las posibilidades de que el riesgo a fallar sea mayor, debido a que, las personas jurídicas poseen responsabilidades que deben cumplir para no incurrir en faltas, tal y como lo estipula el Código Nacional de Procedimientos Penales el cual preveé en el capitulo II sobre procedimiento de las personas jurídicas, es decir, la responsabilidad penal de las empresas, tornándose entonces la prevención el acto más acertado; tomando en cuenta este aspecto, es fácil dilucidar el área de oportunidad y la esquematización de su desarrollo. 
Por otra parte, actualmente la responsabilidad ambiental de las empresas es de observancia puntual para las autoridades, debido a la ya mencionada necesidad e intención de proteger el medio ambiente, por lo que un modelo de compliance, que como se ha dicho anteriormente, colige aspectos normativos pero también éticos, es ideal para atender aspectos fundamentales como la protección y prevención que junto con la reparación del daño unen las medidas que el estado mexicano ha implementado para cumplir con la responsabilidad ambiental.

Al no tener una certeza sobre el concepto y contexto o lugar que ocupa el compliance, las empresas no admiten la necesidad de implementarlo, por lo que se arriesgan a sufrir daños.

En el aspecto ambiental, las empresas deben cuidar su sistema de operación, atendiendo, pero sobre todo, entendiendo las razones para hacerlo; debido a que si se plantea un programa de esta naturaleza, es más facil adecuarse a otro tipo de normas como por ejemplo, las ISO ambientales o entre otras de carácter internacional, cuyo objetivo principal no es que se sancione el daño sino que este no exista y que la cultura de prevención se comparta tanto por directivos como por todo el personal.

A lo largo de este proyecto, se evidenciará la necesidad e importancia de implementar un modelo de compliance ambiental en las empresas para que puedan cumplir facilmente con las normativas nacionales e internacionales atendiendo los derechos humanos, la innovación y el respeto por el medio ambiental. De igual forma, se hará una breve pero completa descripción de la figura del compliance a través de su conceptualización y aplicación en otros países. Se prentende analizar el alcance que posee esta herramienta dentro de la emplresa y la forma en que se desarrolla en conjunto con la legislación aplicable.

Se examinarán los beneficios de la elaboración de un modelo de compliance ambiental para las empresas.

Este proyecto consta de tres apartados en el que se desarrollarán las principales connotaciones que deben tomarse en consideración para la implementación de un modelo de esta índole; en la primera sección se explica detalladamente el concepto, función y 
alcance del compliance, así como el área en el que debe desarrollarse dentro de una empresa.

En el segundo apartado, se mencionan los antecedentes de este modelo y su adecuación tanto para el sistema jurídico anglosajón como su posterior inclusión y adaptación en México a través de distintos preceptos legales.

Por ultimo, se hablará sobre las responsabilidades de las personas juridicas y la forma en que la realizacion de uno de estos modelos puede prevenir y/o reparar conflictos que futuras, lo anterior,-permitirá hacer una conclusión derivada de los aportes de excelentísimos autores y las sencillas reflexiones que se han hecho para tales efectos.

\section{Compliance - concepto y función dentro de la empresa}

Según diversos autores, la traducción literal de 'compliance' que podría ser 'cumplimiento' o 'cumplimiento normativo' como usualmente se denomina en español, es insuficiente para determinar íntegramente lo que significa este modelo, pero, sobre todo, los alcances que posee.

Esto causa confusión entre los interesados, pero, si bien es cierto, hablar de compliance es enunciar todo un sistema de gestión que funciona dentro de la organización de una empresa, el cual conjunta los parámetros que se deben cumplir, así como las formas y que por lo tanto, algunos estarán de acuerdo en que su escueta traducción permite magnificar las funcionalidades y evita la reducción de áreas a las que se dirige este sistema; es por ello, que dicha 'inconsistencia' no debería representar un problema al no saber cómo traducirlo y adaptarlo al español, sino más bien, es menester entender cómo funciona y para qué.

"El compliance es un conjunto de procedimientos y buenas prácticas adoptados por las organizaciones para identificar y clasificar los riesgos operativos y legales a los que se enfrentan y establecer mecanismos internos de prevención, gestión, control y reacción frente a los mismos” (World Compliance Association, 2017a, pág. I) 
El objetivo de un programa de compliance es garantizar que tanto directivos, colaboradores y agentes vinculados, cumplan con el marco normativo vigente, por lo que no deben tomarse en cuenta únicamente preceptos legales y reglamentos, sino también las políticas internas, el compromiso con los clientes, proveedores o terceros y, sobre todo, los códigos éticos. De esta forma, el concepto reúne a la esfera jurídica, a la reguladora y a la esfera de la responsabilidad social empresarial (FFH - Fundació factor humá, 2016, pág. 1).

Además, 'se emplea para describir una amplia variedad de iniciativas de orden económico, social y medioambiental tomadas por empresas, que no se fundan exclusivamente en requisitos jurídicos y son, en su mayoría, de naturaleza voluntaria' (International Labour Organization, 2003, pág. 1).

Por lo tanto, las personas jurídicas tienen a su disposición una extensa cantidad de marcos de referencia en muchos ámbitos de cumplimiento, de entre los cuales se puede destacar los estándares internacionales en derechos humanos como:

- Declaración Universal de los Derechos Humanos

- Pacto internacional de Derechos Civiles y Políticos

- Acuerdo de cooperacion ambiental de america del norte

- Principios rectores sobre empresas y derechos humanos adoptados por el Consejo de Derechos Humanos de las Naciones Unidas

- Pacto internacional de derechos económicos, sociales y culturales

En materia de Compliance:

- ISO 31000 sobre gestión de riesgos

- ISO 19600 sobre sistemas de gestion de cumplimiento

- ISO 26000 sobre responsabilidad social

- ISO 14001 sobre gestión ambiental

- Los principios para un gobierno corporativo de la Organización para la Cooperación y el Desarrollo Económicos (en adelante OECD) 
- Las directrices de OECD para empresas multinacionales incluidas en la Declaración de la OECD sobre inversión internacional y empresas multinacionales

- Informes de sostenibilidad de la Global Reporting Initative

Entre otras, cuyas recomendaciones se sitúan en diversos ámbitos como derechos laborales, seguridad social, medio ambiente, sostenibilidad, etc.

El objetivo principal de un programa de compliance será: instruir, verificar y prevenir, por lo que es muy importante que se tomen en cuenta las herramientas y preceptos mencionados anteriormente para ser adecuados a las funciones y necesidades de cada empresa; sin embargo, no es posible hablar de un modelo general aplicable, sino más bien de guías para realizarlo, ya que cada organización definirá lo que el compliance debe contener.

Otro aspecto que el empresario debe considerar es, que tal y como se mencionó al inicio, el programa debe funcionar en todas las áreas, de ahí que emane la imposibilidad de mezclarlo con manuales de operación o integrarlo a sectores que podrían considerarse similares pero cuya principal diferencia estriba en la aplicación de su trabajo, pues el compliance no se diseña para que opere en un área sino para que estas funcionen en torno al compliance.

Quizás este es el punto de partida de la elaboración de estos programas, ya que el hecho de que sea acatable a todas las áreas indica que tiene que partir de la regulación de conductas y la transmisión de una cultura ética que independientemente de la tarea que se gestione, pueda cumplirse.

El programa de compliance lo puede realizar -independientemente si se habla de una pyme o una organización mas grande-, un despacho de abogados o bien, es adecuado incluso, incorporar la figura del compliance officer cuya función será, además de elaborar un compliance a la medida, verificar las actividades cotidianas que se realizan al interior a fin de poder medir los niveles de riesgos, reeducar conductas y así evitar incumplir, por lo que 
es importante que ya sea el oficial o el despacho jurídico posean un macro dominio de la información de la empresa.

\section{2 Antecedentes y usos en otros países}

El compliance procede del mundo jurídico-empresarial anglosajón, siendo el primer antecedente la Foreign Corrupt Practices Act creada a finales de los años 70's en Estados Unidos debido a dos hechos importantes: el caso Watergate y la campaña "promovida" por la URSS a nivel mundial, en el cual, se denunciaron las prácticas de corrupción que utilizaban las multinacionales americanas, especialmente en los países en vías de desarrollo (Bonatti, 2019) con el propósito de 'hacer ilegal que ciertas clases de personas y entidades realicen pagos a funcionarios de gobiernos extranjeros para ayudarlos a obtener o retener negocios' (World Compliance Association, 2019b) además, en este documento se incorpora la figura del compliance officer.

Actualmente, México utiliza mayormente los programas de compliance para regular sus prácticas y para trabajar con empresas transnacionales de quienes exige contar con este programa por lo que, si no es existente, la empresa podría perder una oportunidad.

A partir de este suceso, surgieron diversas leyes, reglamentos y directrices como la Markets in Financial Instruments Directive (MIFID) a finales de los 90's, cuyo objetivo es reforzar requisitos de organización y operación de parte de los proveedores de servicios de inversión, así como el perfeccionamiento de las normas de conducta que rigen sus relaciones con los usuarios (Unión Europea Law, 2016).

En 2010, con la entrada en vigor de la reforma del Código Penal español se añadió a su contenido la responsabilidad penal de las personas jurídicas, en donde asumen un tipo de responsabilidad penal 'por las acciones delictivas que pudieran ocurrir en la actividad empresarial así como por las actividades de los empleados’ (Jefatura del estado, 2010, pág. VII) pero también, se señala que puede haber una atenuación de la pena a la persona jurídica o inclusive, la exclusión de la responsabilidad penal cuando demuestre que antes del proceso de investigación, la empresa contaba con un programa de compliance en donde se prevén estos aspectos y que por lo tanto la falla cometida por parte de un colaborador no 
es culpa de la empresa sino que este ha cometido un hecho doloso porque no siguió lo estipulado en el programa establecido coincidiendo con (Jiménez, 2018). Este aspecto es importante tomarlo como referencia, puesto que se puede dilucidar el alcance que podría llegar a tener un modelo de compliance bien elaborado.

En 2014 se promulgó 'la ley 31/2014 sobre sociedades de capital para la mejora del gobierno corporativo que comprende diferentes y novedosas obligaciones para los administradores a partir del desarrollo del concepto de la diligencia debida en el desempeño del cargo de administrador' (World Compliance Association, 2017b, pág. III) y al año siguiente, se incorporaron al ordenamiento jurídico los programas de compliance como instrumento para eludir o atenuar dicha responsabilidad, ante la comisión de un grupo cerrado de delitos (World Compliance Association, 2019b).

En Chile, durante el 2010 se creó la Ley de responsabilidad penal de las personas jurídicas donde señala que las organizaciones podrían ser responsables de los delitos que cometan sus colaboradores si no poseen algun plan para prevenir estos actos puesto que se podría asumir que fueron parte de la comisión del delito. Actualmente, se deben certificar sus programas de compliance ante el gobierno para asegurar que se encuentran en un correcto marco de legalidad.

\section{Alcances: responsabilidad de la persona jurídica - beneficios de realizar un compliance}

Se ha mencionado que las personas jurídicas disponen de diversos marcos de referencia para su cumplimiento normativo, mismos que pueden ser excelentes auxiliares al momento de llevar a cabo la creación de un programa de compliance, pero también, hay que mencionar que la existencia de todas estas disposiciones se debe en gran parte, a que el nivel de alcance que las organizaciones pueden llegar a poseer conlleva un grado alto de responsabilidad, por lo que se deben regular y verificar sus actuaciones, con el propósito de proteger en todo momento, la integridad y dignidad humana.

Actualmente, son listas extensas de lineamientos a los que las empresas se deben adherir y no es para menos, pues todos son el resultado de análisis minuciosos sobre el impacto que 
una organización posee dentro de la sociedad y como puede determinar incluso -sin exagerar- el rumbo de la historia. Este hecho está completamente relacionado con la evolución de los derechos humanos, por lo que se torna urgente que las personas jurídicas entiendan la importancia de sus actuaciones y los efectos positivos tanto para el estado como para ellos mismos, al tener la posibilidad de prevenir oportunamente en vez de intentar reparar un daño cuyas probabilidades de solucionarse oportunamente, sean escasas.

Enfocándose en el medio ambiente, se puede dimensionar el alto grado de importancia que tiene tan solo con notar que el derecho al medio ambiente sano es de carácter fundamental a nivel internacional al ser la base para la existencia humana. El nivel de control que una empresa posea sobre su gestión de cuidado al medio ambiente no solo contribuirá al cumplimiento de un derecho bien establecido, sino que también, traerá consigo diversos estímulos de carácter económico y social, pero lo más importante, evitará que la empresa se vea inmiscuida en graves conflictos.

La responsabilidad ambiental se ha convertido en un tema de trabajo por las entidades gubernamentales de prácticamente todas las naciones. Al ser complejo y urgente, los mecanismos de vigilancia se han multiplicado y aunque existen inconsistencias dentro de ellos, la imposición de un castigo (traducido en multa o sanción) es real.

El alcance legal, abarca más de una rama jurídica y más de un tipo de castigo. La ley establece que, en materia ambiental, existe responsabilidad de tres tipos: administrativa, civil y penal y es que, si bien es cierto, aunque en México no existe como tal una cultura de legalidad propiamente establecida y determinada en el marco empresarial, que direccione a un modelo de compliance, el no tener la figura de persona jurídica como acreedor para las sanciones estipuladas podría eximirlas de algunas, pero no todas, como es en el caso de la responsabilidad penal de las personas jurídicas mencionada al inicio de este trabajo que se origina por la violación a bienes jurídicos socialmente reconocidos que merecen una tutela específica; 'la violación a estos es de tal magnitud, que amerita una sanción de mayor rigor y trascendencia' (Paul, 2015). 
Por lo tanto, un procedimiento especial para las personas jurídicas estará encaminado a todos aquellos que dañen bienes jurídicos como la vida, la salud, la economía, etc., por lo que el catálogo de delitos es amplio y resulta entonces un punto importante para el representante de la empresa conocer, pero, sobre todo, atender la gestión de las actividades.

La Convención de las Naciones Unidas contra la Delincuencia Organizada Transnacional y sus Protocolos, establece dentro del artículo $10^{\circ}$ Oficina de las Naciones Unidas contra la Droga y el Delito (UNODC, 2004a): la responsabilidad jurídica de las personas jurídicas, mencionando que:

1. Cada Estado Parte adoptará las medidas que sean necesarias, de conformidad con sus principios jurídicos, a fin de establecer la responsabilidad de personas jurídicas por participación en delitos graves en que esté involucrado un grupo delictivo organizado, así como por los delitos tipificados con arreglo a los artículos 5, 6, 8 y 23 de la presente Convención.

2. Con sujeción a los principios jurídicos del Estado Parte, la responsabilidad de las personas jurídicas podrá ser de índole penal, civil o administrativa.

3. Dicha responsabilidad existirá sin perjuicio de la responsabilidad penal que incumba a las personas naturales que hayan perpetrado los delitos.

4. Cada Estado Parte velará en particular por que se impongan sanciones penales o no penales eficaces, proporcionadas y disuasivas, incluidas sanciones monetarias, a las personas jurídicas consideradas responsables con arreglo al presente artículo.

Igualmente, el apartado dedicado a la responsabilidad de las personas jurídicas incluido en la Convención de las Naciones Unidas contra la Corrupción dentro del artículo 26 recomienda a los estados parte, adoptar las medidas necesarias para establecer la responsabilidad de las personas jurídicas por ser partícipes en delitos tipificados con arreglo a la presente Convención y además, menciona que este tipo de responsabilidad existe sin perjuicio de que la responsabilidad penal que incumba a las personas naturales que hayan 
cometido los delitos, donde además, las sanciones deben ser proporcionadas y disuasivas, incluyendo las sanciones monetarias.

En México, el Código Nacional de Procedimientos Penales prevé este tipo de responsabilidad en el capítulo II sobre el procedimiento para las personas jurídicas en donde establece en el artículo 421 que:

Las personas jurídicas serán penalmente responsables, de los delitos cometidos a su nombre, por su cuenta, en su beneficio o a través de los medios que ellas proporcionen, cuando se haya determinado que además existió inobservancia del debido control en su organización. Lo anterior con independencia de la responsabilidad penal en que puedan incurrir sus representantes o administradores de hecho o de derecho (Código Nacional de Procedimientos Penales, 2020)

De tal suerte, que si se plantea que la investigacion que se realiza sobre la empresa no tiene consecuencias graves, esta debería acreditar su programa de compliance; si no lo tiene, entonces la situación se complicaría al no probar su compromiso moral y legal.

Dentro de este capítulo se establece las diversas sanciones a las que se pueden hacer acreedores las personas jurídicas, que son

I. Sanción pecuniaria o multa;

II. Decomiso de instrumentos, objetos o productos del delito;

III. Publicación de la sentencia;

IV. Disolución, o

V. Las demás que expresamente determinen las leyes penales conforme a los principios establecidos en el presente articulo, además de otras consecuencias jurídicas como la clausura del establecimiento, imposibilidad de participar en actividades como licitaciones públicas, intervención judicial para salvaguardar los derechos de los trabajadores o de los acreedores o amonestación pública 
(Código Nacional de Procedimientos Penales, 2020, art. 422)

En el caso de los delitos contra el ambiente, el Código Penal Federal prevé de igual forma, en el título vigésimo quinto todo lo relacionado con delitos contra el ambiente y la gestión ambiental.

Por otro lado, la Ley de Responsabilidad ambiental, establece en su artículo 25 que:

Los daños ocasionados al ambiente serán atribuibles a la persona física o moral que omita impedirlos, si ésta tenía el deber jurídico de evitarlos. En estos casos se considerará que el daño es consecuencia de una conducta omisiva, cuando se determine que el que omite impedirlo tenía el deber de actuar para ello derivado de una Ley, de un contrato, de su calidad de garante o de su propio actuar precedente. (Ley Federal de Responsabilidad Ambiental, 2013)

Asimismo, en el artículo 52 de la misma ley se establece que:

Las disposiciones del presente Titulo serán aplicables a los conflictos penales y los procedimientos derivados de la comisión de delitos contra el ambiente y la gestión ambiental, de conformidad a lo previsto por el Código Penal Federal y el Código Federal de Procedimientos Penales. La reparación y compensación de los daños ocasionados al ambiente, que proceda en términos del Título Vigésimo Quinto del Código Penal Federal, se llevarán a cabo con arreglo a lo previsto por el artículo 3o. de esta Ley y las disposiciones del presente Título. El Ministerio Público está obligado a solicitar de oficio la reparación y compensación de los daños ocasionados al ambiente. (Ley Federal de Responsabilidad Ambiental, 2013)

Lo anterior, atiende uno de los principios básicos en materia de daño ambiental que determina que 'el que contamina, paga'. Este se traduce en la obligación de responder por un daño causado al medio ambiente, aunque no haya existido intención de causarlo.

La Ley General de Equilibrio Ecológico y Protección al Medio Ambiente lo indica en el artículo 171 que a la letra dice: 
Las violaciones a los preceptos de esta Ley, sus reglamentos y las disposiciones que de ella emanen serán sancionadas administrativamente por la Secretaría, con una o más de las siguientes sanciones: [...] multa, clausura, arresto, decomiso y suspensión o revocación; tal y como lo podemos apreciar en la figura 1.

\section{Figura 1.}

Consecuencias jurídicas en materia ambiental para las empresas

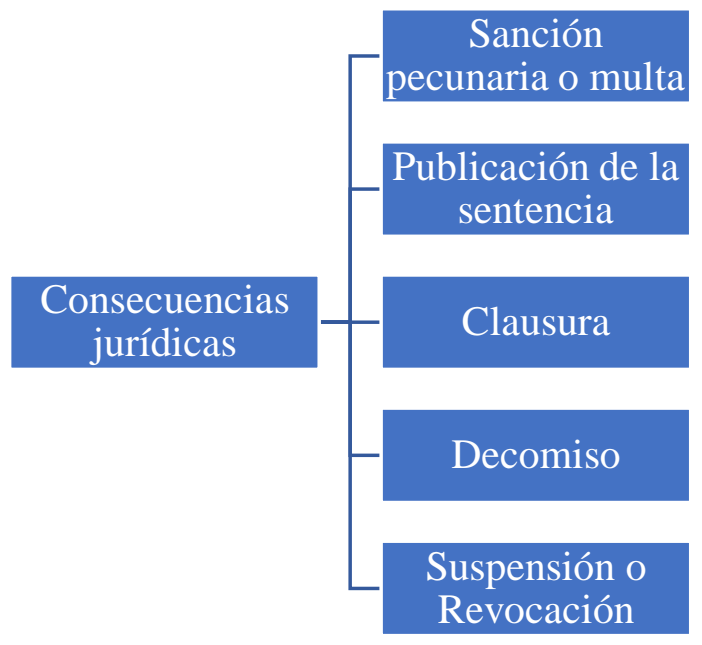

Fuente: Ley General de Equilibrio Ecológico y Protección al Medio Ambiente

En tanto, esta ley también preveé los delitos del orden federal en materia ambiental que son todos 'aquellos casos en que, como resultado del ejercicio de sus atribuciones, la Secretaría tenga conocimiento de actos u omisiones que pudieran constituir delitos conforme a lo previsto en la legislación aplicable, formulará ante el Ministerio Público Federal la denuncia correspondiente' (Ley General del Equilibrio Ecológico y la Protección al Ambiente, 2018, art. 182)

Igualmente, el Código Penal Federal, establece en el artículo 420 fracc. V las penas a las que se puede hacer acreedor aquel que 'no realice o cumpla las medidas técnicas, correctivas o de seguridad necesarias para evitar un daño o riesgo ambiental que la autoridad administrativa o judicial le ordene o imponga'. (Código Penal Federal, art. 420 fracc. V) 


\section{Figura 2.}

Tipos de responsabilidad empresarial en materia ambiental y sus consecuencias

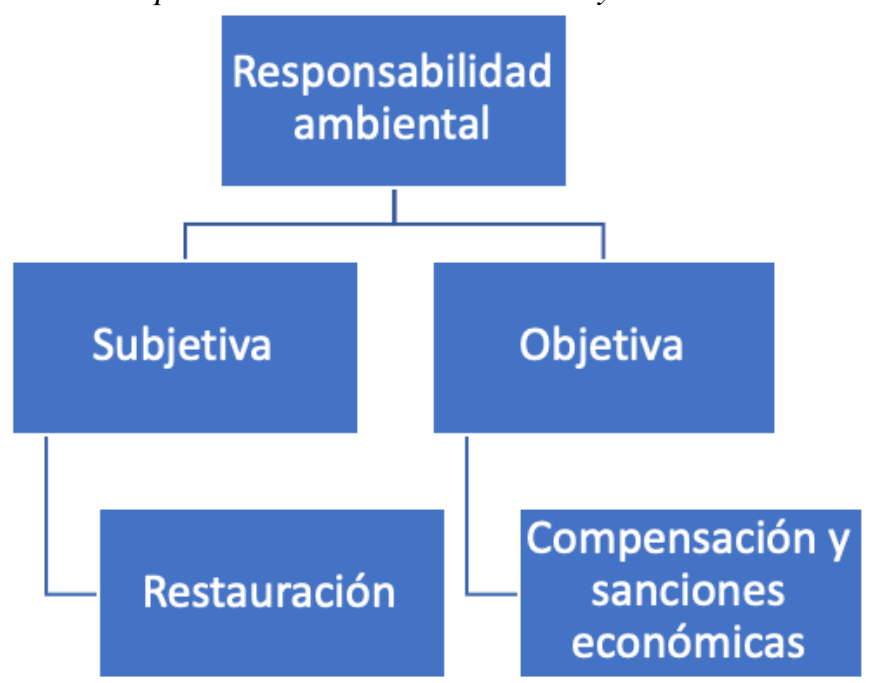

Fuente: Código Penal Federal

Tomando en cuenta estos parámetros, las razones de crear un programa de compliance enfocado en materia ambiental, independientemente del giro de la empresa, son obvias. Otro factor importante que el compliance atiende y que va de la mano con lo estipulado en las leyes es que independientemente si se sancione o no, las empresas deben responder, hoy más que nunca al crecimiento de la mano del desarrollo sustentable que es:

El proceso evaluable mediante criterios e indicadores del carácter ambiental, económico y social que tiende a mejorar la calidad de vida y la productividad de las personas, que se funda en medidas apropiadas de preservación del equilibrio ecológico, protección del ambiente y aprovechamiento de recursos naturales, de manera que no se comprometa la satisfacción de las necesidades de las generaciones futuras' (Ley General del Equilibrio Ecológico y la Protección al Ambiente, 2018, art. Art. $3^{\text {a }}$ fracc. XI)

Pues si bien las empresas esperan no enfrentar situaciones negativas que les genere un daño, ocuparse de la sustentabilidad atendería el respeto que deben tener por todos los colaboradores, por los derechos y por las generaciones futuras e incrementaría la seguridad de permanencia dentro del mercado, así como su reconocimiento y crecimiento. 
Además de los preceptos que se enlistan en el primer apartado, para el tema que se estudia preciso revisar la resolución aprobada por la Asamblea General de las Naciones Unidas en julio de 2012 durante la Conferencia Rio+20, en la que se manifestó lo siguiente:

Reconocemos la importancia de la presentación de informes sobre sostenibilidad empresarial y alentamos a las empresas, especialmente a las que cotizan en bolsa y a las grandes empresas, a que, según proceda, consideren la posibilidad de incorporar información sobre sostenibilidad a su ciclo de presentación de informes. Alentamos a la industria, los gobiernos y las partes interesados pertinentes a que, con el apoyo del sistema de las Naciones Unidas, según proceda, confeccionen modelos de mejores practicas y faciliten la adopción de medidas en favor de la incorporación de informes sobre sostenibilidad, teniendo en cuenta las experiencias de los marcos ya existentes y prestando especial atención a las necesidades de los países en desarrollo, incluso en materia de creación de capacidad (Naciones Unidas, 2012)

Por lo que, las compañías líderes en el mundo han incorporado la responsabialidad Social Empresarial a su estrategia de negocios como elemento diferenciador y como ventaja competitiva, con resultados financieros positivos. Cada vez más estudios 'comprueban la correlación positiva entre los resultados económicos y financieros y el comportamiento socialmente responsable de la empresa' (Cajiga, 2020, pág. 11).

En cuanto a la responsabilidad civil que puede derivar de una obligación principal incumplida, 'ya sea por una obligación legal o por el incumplimiento contractual, en ambos casos se genera la obligación de la reparación del daño causado’ (Fernández, 2017, pág. 174).

La responsabilidad civil está regulada en el Código Civil federal en el artículo 1910, que a la letra dice: 'el que obrando ilícitamente o contra las buenas costumbres cause daño a otro, está obligado a repararlo, a menos que demuestre que el daño se produjo como consecuencia de culpa o negligencia inexcusable de la víctima' (Código Civil Federal, 2019, art. 1910), 'la reparación del daño debe consistir a elección del ofendido en el 
restablecimiento de la situación anterior, cuando ello sea posible, o en el pago de daños y perjuicios (Código Civil Federal, 2019, art. 1915).

En cuanto a la responsabilidad administrativa, la Ley General de Responsabilidades Administrativas prevé en su artículo 24 lo siguiente:

Las personas morales serán sancionadas en los términos de esta Ley cuando los actos vinculados con faltas administrativas graves sean realizados por personas físicas que actúen a su nombre o representación de la persona moral y pretendan obtener mediante tales conductas beneficios para dicha persona moral.

Sin embargo, el artículo 25 menciona que: 'en la determinación de la responsabilidad de las personas morales a que se refiere la presente Ley, se valorará si cuentan con una política de integridad' (Ley General de Responsabilidades Administrativas). Estas politicas de integridad a las que se refiere 'son un manual de organización y procedimientos que sea claro y completo, en el que se delimiten las funciones y responsabilidades de cada una de sus áreas, y que especifique claramente las distintas cadenas de mando y de liderazgo en toda la estructura'; sistemas de de control, vigilancia y auditoría, de denuncia y procesos adecuados de entrenamiento y capacitación respecto de las medidas de integridad.

Los Principios Marco sobre los Derechos Humanos y el Medio Ambiente en Naciones Unidas Derechos Humanos Procedimientos Especiales (OHCHR, 2018) mencionan que:

Las empresas deben realizar evaluaciones del impacto en los derechos humanos de conformidad con los Principios Rectores sobre las Empresas y los Derechos Humanos, según los cuales las empresas "deben identificar y evaluar las consecuencias negativas reales o potenciales sobre los derechos humanos en las que puedan verse implicadas ya sea a través de sus propias actividades o como resultado de sus relaciones comerciales'; incluir 'consultas sustantivas con los grupos potencialmente afectados y otras partes interesadas'; e 'integrar las conclusiones de sus evaluaciones de impacto en el marco de las funciones y procesos internos pertinentes y tomar las medidas oportunas. 
Para cumplir con lo recomendado por la Organización de las Naciones Unidas, es acertado evaluar la empresa mediante una auditoria ambiental, la cual 'es una vía voluntaria y diferente a las acciones de inspección y vigilancia, promueve la identificación de oportunidades de mejora, así como la instrumentación de proyectos que reducen la contaminación e incrementan la competitividad. Las auditorías ambientales revisan dos aspectos; el cumplimiento de la ley y la implementación de buenas prácticas ambientales' (Procuraduría Federal de Protección al Ambiente, 2010).

Estas auditorías, a la vez, cumplen con lo establecido por la norma ISO 14001 y lo establecido en otras reglamentaciones, por lo que la empresa puede obtener certificaciones verde reconocidas a nivel internacional y que instantáneamente le otorga un valor económico y social más alto. Estos certificados aluden al respeto por los derechos humanos, la atención por los vertigininosos cambios del ritmo actual de vida, un incremento en el alcance de oportunidades de acceso y evolución para distintos sectores poblacionales, en una cultura de valores y educación necesaria actualmente y al desarrollo sostenible que de conformidad 'con el informe Brundtland de 1987, la sostenibilidad consiste en 'satisfacer las necesidades de la actual generación sin sacrificar la capacidad de futuras generaciones de satisfacer sus necesidades' (Brundtland, 1987).

\section{METODOLOGÍA, TÉCNICA Y MATERIALES EMPLEADOS}

Se utilizarán los siguientes métodos de investigación:

Método dogmático: se realizará un análisis de diversas leyes, su aplicación y la relación que poseen con los programas de compliance para las empresas y la forma en que este puede facilitar el cumplimiento normativo y de principios éticos para privilegiar la supremacía del bienestar social y a partir de ello, enfatizar la importancia del aspecto ambiental para la construcción de compliance.

Aplicaremos el método histórico para analizar algunos acontecimientos y actuaciones que demostraron la importancia de gestionar un modelo de compliance en las empresas con un enfoque cualitativo y axiológico. 


\section{CONCLUSIONES}

El compliance funciona para luchar contra prácticas delictivas pero además, para arreglar defectos de organización en el marco de la empresa, implementar medidas basicas para que los productos o servicios que se ofrezcan cumplan con estándares de calidad que permitan incrementar su valor; además, gracias a este programa, los empresarios pueden tomar decisiones inteligentes que ayuden a alcanzar sus objetivos como la incorporación de cursos de capacitación, mecanismos de regulacion y elaboración de protocolos para proyectar la empresa hacia las necesidades del futuro, pero sobre todo, priorizando la ética y la adopción de valores que protegen los derechos humanos y el cuidado por el medio ambiente.

\section{REFERENCIAS}

Bonatti, F. (mayo de 2019). Bonet. Obtenido de https://www.bonattipenal.com/legal-compliance-iuna-breve-historia/

Brundtland, H. (1987). Informe Brundtland. Tokio: Comisión Mundial Para el Medio Ambiente y el Desarrollo de la ONU.

Cajiga Calderón, J. F. (mayo de 2020). Centro Mexicano para la Filantropia (CEMEFI). Obtenido de El concepto de responsabilidad social empresarial: https://www.cemefi.org/esr/images/stories/pdf/esr/concepto_esr.pdf

Código Civil Federal. (03 de junio de 2019). Diario Oficial de la Federación. México, México: Cámara de Diputados del H. Congreso de la Unión.

Código Nacional de Procedimientos Penales. (22 de enero de 2020). Diario Oficial de la Federación. México, México: Cámara de Diputados del H. Congreso de la Unión.

Código Penal Federal. (s.f.).

Federación, D. O. (s.f.). Ley General de Responsabilidades Administrativas.

Fernández, A. (2017). Instituto de Investigaciones Jurídicas de la UNAM. Recuperado el mayo de 2020, de La Responsabilidad Civil Subjetiva: https://archivos.juridicas.unam.mx/www/bjv/libros/9/4488/10.pdf

FFH - Fundació factor humá. (junio de 2016). factorhuma.org. Obtenido de Unidad de conocimiento: https://factorhuma.org/attachments/article/12429/compliance_cast.pdf

Https://www.unodc.org/documents/mexicoandcentralamerica/publications/Corrupcion/Convencion _de_las_NU_contra_la_Corrupcion.pdf. (2004a). Organización de las Naciones Unidas. Recuperado el mayo de 2020, de https://www.unodc.org/documents/mexicoandcentralamerica/publications/Corrupcion/Conv encion_de_las_NU_contra_la_Corrupcion.pdf 
International Labour Organization. (noviembre de 2003). Nota informativa sobre responsabilidad social de la empresa y normas internacionales del trabajo. Obtenido de International Labour Organization:

https://www.ilo.org/public/spanish/standards/relm/gb/docs/gb288/pdf/sdg-3.pdf

Jefatura del estado. (22 de junio de 2010). Ley Orgánica 5/2010 . Ley Orgánica 5/2010, de 22 de junio, por la que se modifica la Ley Orgánica 10/1995, de 23 de noviembre, del Código Penal. Madrid.

Jiménez, C. V. (2018). Los requisitos mínimos de un programa de Compliance. Escura.

Naciones Unidas (2012). Resolución 66/288 aprobada por la Asamblea General el 27 de julio de 2012. (27 de julio de 2012).

Oficina de las Naciones Unidas Contra la Droga y el Delito. (2004a). Convención de las Naciones Unidas contra la Delincuencia Organizada Transnacional y sus Protocolos.

Oficina de las Naciones Unidas Contra la Droga y el Delito. (2004b). Convención de las Naciones Unidas contra la Delincuencia Organizada Transnacional y sus Protocolos.

OHCHR-Naciones Unidas Derechos Humanos Procedimientos Especiales (2018). Principios Marco sobre los Derechos Humanos y el Medio Ambiente

Paul, M. B. (2015). La responsabilidad penal de las personas morales en México. México: Porrúa.

Principios Marco sobre los Derechos Humanos y el Medio Ambiente. (2018). Naciones Unidas Derechos Humanos Procedimientos Especiales. Recuperado el mayo de 2020, de Organización de las Naciones Unidas: https://www.ohchr.org/Documents/Issues/Environment/SREnvironment/FP_ReportSpanish. PDF

Procuraduría Federal de Protección al Ambiente. (2010). Gobierno Federal. Recuperado el mayo de 2020, de Auditorías ambientales: http://www.profepa.gob.mx/innovaportal/v/542/1/mx.wap/la_auditoria_am

Resolución 66/288 aprobada por la Asamblea General el 27 de julio de 2012. (27 de julio de 2012). Naciones Unidas. Obtenido de Asamblea general de las Naciones Unidas: https://undocs.org/es/A/\%20RES/66/288

Unión Europea Law. (11 de Octubre de 2016a). EUR-LEX Access to European Union Law. Obtenido de EUR-LEX Access to European Union Law: https://eur-lex.europa.eu/legalcontent/EN/TXT/?uri=LEGISSUM\%3Al24036e

World Compliance Association. (enero de 2017b). World Compliance Association. Obtenido de Compliance Corporativo: http://www.worldcomplianceassociation.com/que-escompliance.php

World Compliance Association. (mayo de 2019b). Guía de implementación de compliance para pymes. Obtenido de World Compliance Association:

http://www.worldcomplianceassociation.com/documentacion/Guia_Compliance_web_com pressed.pdf

World Compliance Association. (mayo de 2019a). The United States Departament of Justice. Obtenido de Official website of the United States government: Foreign Corrupt Practices Act 